American J. of Engineering and Applied Sciences 1 (4): 295-301, 2008

ISSN 1941-7020

(C) 2008 Science Publications

\title{
Combustion of Bimodal Nano/Micro Aluminum Suspension with New Reaction Rate Model
}

\author{
${ }^{1}$ M. Bidabadi, ${ }^{1}$ N. Moallemi, ${ }^{1}$ I. Shafieenejad and ${ }^{2}$ M. Jadidi \\ ${ }^{1}$ Department of Mechanical Engineering, \\ Iran University of Science and Technology, Combustion Research Laboratory, Tehran, Iran \\ ${ }^{2}$ Department of Aerospace Engineering, K.N. Toosi University of Technology, Tehran, Iran
}

\begin{abstract}
In this study a mathematical model for combustion of bimodal particle in lean flow was developed. The difference between structure of flame in this work and previous ones was that, in those flame was divided by five zones and reaction rate was considered to be constant in reaction zones and also zero in post flame zone. In reality it was obvious with respect to shape and size of different particles in dust, reaction didn't end suddenly. In the present research the heat loss term, which was assumed to be linearly proportional to temperature difference, was added to the energy conservation equation and reaction rate was considered proportional to available amount of fuel, leading to exponentially decreasing of reaction rate. The flame speed and temperature distribution were obtained by solving the energy equation in each zone and matching the temperature and heat flux at the interfacial boundaries. Calculated values of flame speed were in good agreement with experimental data.
\end{abstract}

Key words: Dust combustion, binary suspension, heat loss, flame speed, reaction rate

\section{INTRODUCTION}

The majority of practical applications of aluminum combustion such as solid rocket motors, dust explosions in industry and chemical reactors involve combustion of dust suspensions of small particle sizes ${ }^{[1-4]}$. The existing experimental and theoretical literature on the other hand, is mostly dedicated to the study of the combustion of isolated and relatively large particles ${ }^{[5]}$. It has already been suggested that extrapolation of the results obtained with large particles towards small particles is questionable due to possible changes in the combustion mechanisms ${ }^{[6-9]}$. Recently, aluminum nanopowders became available and attracted significant interest in the advanced energetic community. While combustion of volatile, polydisperse sprays have been numerically investigated in several works ${ }^{[10,11]}$, flame propagation in a non-volatile multi-size dust suspension has yet to be addressed. Risha et al. ${ }^{[12]}$ recently examined the flame characteristics of bimodal nano and micro-sized aluminum particle/air laden flows using a Bunsen-burner type apparatus, similar to the experiment of Goroshin et al. ${ }^{[13]}$. Combustion of dualfuel particle-laden flows was also examined by Boichuk et al. ${ }^{[14]}$ for aluminum-boron dust mixtures and by Goroshin et al. ${ }^{[15]}$ for aluminum-manganese dust mixtures. Huang et al. ${ }^{[16]}$ examined various parameters, such as the particle composition, equivalence ratio and particle size, on the burning behavior of bimodal aluminum particle/air mixtures in detail. In the present work, a mathematical combustion model of bimodal solid particles is investigated. In the previous theoretical models ${ }^{[15,16]}$, the heat loss term was neglected and reaction rate is constant during reaction. In this research the heat loss term was determined by considering the heat transfer contents to surrounding surfaces and reaction rate is decrease by decreasing of amount of mass.

\section{THEORETICAL ANALYSIS BASED ON NEW REACTION RATE MODEL}

The flame model in a binary suspension is developed in this study which is based on a simple description of binary suspension dust flame that was previously used by Goroshin et $a l^{[15]}$ and Huang et al. ${ }^{[16]}$. The combustion equations of premixed dust cloud in laminar flame are studied for both lean and rich mixture. In rich mixture, combustion begins at a moment and reaction rate is considered proportional to available amount of oxygen which leads to exponentially decrease of reaction rate. But in lean

Corresponding Author: N. Moallemi, Department of Mechanical Engineering, Iran University of Science and Technology, Combustion Research Laboratory, Tehran, Iran Tel: +982177240197 Fax: +982172209019 
mixture, flame structure is so considered that combustion starts at a moment and ends suddenly at another moment. However since a controller of reaction rate is available amount of fuel and regarding to different shape and size of particles ${ }^{[17,18]}$ it is obvious that combustion cannot particularly end up suddenly and afterwards there must be reaction in post flame zone. In this study reaction rate is proportional to available amount of fuel. Actually in rich mixture, the reaction rate controller is amount of oxygen and in lean mixture, available amount of fuel. In the following we consider reaction rate proportional to available amount of fuel per unit volume:

$$
\mathrm{W}_{\mathrm{F}}(\mathrm{t})=\mathrm{A}_{1} \sigma(\mathrm{t})
$$

On the other hand, the fuel quantity as a function of time can be calculated by:

$$
\sigma(t)=\sigma-\int_{t=0}^{t=t} W_{F}(t) d t
$$

where, $\sigma$ is fuel mass fraction at time $t=0$. For solving the above equations to obtain reaction rate two constraints are needed. The first equation is that integrals of reaction rate from $\mathrm{t}=0$ to the end of reaction has to be equal to total available fuel quantity at the first moment:

$$
\sigma=\int_{t=0}^{t=\infty} W_{F}(t) d t
$$

To obtain the second constraint, reaction rate value in the beginning of reaction is considered to be $\sigma / \tau_{\mathrm{c}}$ ( $\tau_{\mathrm{c}}$ is burning time of single particle). By solving Eq. 1 and 2 with constraints and also changing variable the reaction rate is obtained:

$$
\mathrm{W}_{\mathrm{F}}(\mathrm{y})=\frac{\sigma}{\tau_{\mathrm{c}}} \exp (-\mathrm{y})
$$

Flame propagation in this kind of mixture with considerable oxygen excess has been examined. Based on previous model ${ }^{[15,19]}$ in a mono-dispersed aluminum particle-laden flow, the flame usually consists of three zones: the preheat, reaction and post flame zone. The first zone is preheat zone $(\mathrm{y}<0)$ when the temperature of particles is lower than the ignition temperature and the rate of reaction is equal to zero. The second zone is the reaction zone, $(0<y<1)$ where the particles burn in the diffusion regime and the particles temperature remains approximately constant. The third zone is the post flame zone $(1<y)$ where the temperature of gas decreases asymptotically to the ambient temperature at infinity due to non-adiabatic condition. By using continues model for reaction rate we don't have post flame zone and reaction is existed in this domain. The flame speed, flammability limits and temperature distribution are derived by solving the energy equation in each zone and matching the temperature and heat flux at the interfacial boundaries. Goroshin et al. ${ }^{[16]}$ shown that the equation governing heat diffusivity in this problem can be transformed into a linear form by introducing an independent variable $\mathrm{x}$ that is related to the spatial coordinate $x^{\prime}$ as $x=\int_{0}^{x^{\prime}}\left(\rho / \rho_{u}\right) d x$. The gasphase governing equations for mass and energy conservation can be written as follows ${ }^{[20]}$ :

$$
\begin{gathered}
\rho v=\rho_{\mathrm{u}} \mathrm{s}_{\mathrm{L}} \\
\rho v \mathrm{C}_{\mathrm{p}} \frac{\mathrm{dT}_{\mathrm{g}}}{\mathrm{dx}}=\frac{\lambda \mathrm{d}^{2} \mathrm{~T}_{\mathrm{g}}}{\mathrm{dx}^{2}}+\mathrm{w}_{\mathrm{F}} \mathrm{Q}-\alpha\left(\mathrm{T}_{\mathrm{g}}-\mathrm{T}_{\mathrm{u}}\right)
\end{gathered}
$$

where, $\rho, \mathrm{v}$ and $\mathrm{T}$ are the gas density, velocity and temperature, respectively. The subscript $\mathrm{g}$ and $\mathrm{u}$ donate gas and the unburned mixture, $\mathrm{S}_{\mathrm{L}}$ denotes the flame speed, $C_{p}$ the specific heat of gas at constant pressure, $r$ the radius of particle, $\mathrm{w}_{\mathrm{F}}$ the mass consumption rate of particle and $Q$ the heat of reaction per unit mass of fuel. The heat transfer coefficient between gas and walls sides is computed in the following way:

$$
\alpha=\frac{b^{\prime} \lambda}{d^{2}}
$$

where, $d$ is the width of the channel and $b^{\prime}$ is equal to $8^{[21]}$. Because of oxygen excess, the decreasing of oxygen concentration in the flame is small and the burning time of particles in the reaction zone is the same as that for a single particle under initial oxygen concentration $^{[22]}$.

The equation state for an isobaric system is:

$$
\rho \mathrm{T}=\mathrm{const}
$$

By considering the heat transfer between gas and particle generally, we have:

$$
\rho_{\mathrm{s}} \mathrm{vC}_{\mathrm{s}} \frac{\mathrm{dT}_{\mathrm{s}}}{\mathrm{dx}}=\mathrm{n}_{\mathrm{p}} 2 \mathrm{Nu} \pi \mathrm{r} \lambda\left(\mathrm{T}_{\mathrm{g}}-\mathrm{T}_{\mathrm{s}}\right)
$$

where, $\mathrm{C}_{\mathrm{s}}$ is the specific heat of particles, $\rho_{\mathrm{s}}=\mathrm{n}_{\mathrm{P}} \rho_{\mathrm{a}} 4 \pi \mathrm{r}^{3} / 3$ is the bulk density of particles (mass of particles per unit volume), $\rho_{\mathrm{a}}$ is the material density of 
aluminum and $n_{p}$ the number density of particle. The Nusselt number is assumed to be equal to 2 for this analysis ${ }^{[23,24]}$. The nondimensional form of governing equation is defined as:

$$
\begin{aligned}
& \frac{\mathrm{d}^{2} \theta}{\mathrm{dy} \mathrm{y}^{2}}-\mathrm{k} \frac{\mathrm{d} \theta}{\mathrm{dy}}=\mathrm{k} \eta(\theta-1)+ \\
& \mathrm{W}\left\{\begin{array}{lr}
0 & -\infty<\mathrm{y}<0 \\
-\mu \varphi \mathrm{k}\left(\theta_{\mathrm{s}}^{\mathrm{i}}-1\right) \cdot \exp (-\mathrm{y}) & 0<\mathrm{y}<+\infty
\end{array}\right.
\end{aligned}
$$

Here a nondimensional gas temperature $\theta$ is defined as $\theta=\mathrm{T}_{\mathrm{g}} / \mathrm{T}_{\mathrm{u}}$. $\mathrm{y}$ is a nondimensional coordinate defined as $\mathrm{y}=\mathrm{x} / \mathrm{s}_{\mathrm{L}} \tau_{\mathrm{c}}$ (where $\tau_{\mathrm{c}}$ is total particle combustion time). Parameter $\mathrm{k}$ is a nondimensional flame speed, $\mathrm{k}=\mathrm{s}_{\mathrm{L}}^{2} \tau_{\mathrm{c}} / \alpha_{\mathrm{u}}$. Parameter $\mu$ is a nondimensional dust concentration defined as: $\mu=\sigma_{\mathrm{st}} \mathrm{Q} / \mathrm{c}_{\mathrm{P}} \rho_{\mathrm{gu}}\left(\mathrm{T}_{\mathrm{si}}-\mathrm{T}_{\mathrm{u}}\right)$, the subscript st donates Stoichiometric. $\quad \theta_{\mathrm{s}}^{\mathrm{i}}$ is nondimensional ignition temperature of solid particles. The heat loss parameter is the ratio of particle combustion time to time of heat transfer in the channel $\left(\eta=b^{\prime} \alpha \tau_{c} / d^{2}\right)$. The dimensionless energy conservation equation for the solid phase is:

$$
\frac{\mathrm{d} \theta_{\mathrm{s}}}{\mathrm{dy}}=\frac{\theta-\theta_{\mathrm{s}}}{\xi} \quad-\infty<\mathrm{y}<0
$$

where, $\xi=\left[\left(\mathrm{r}^{2} \mathrm{c}_{\mathrm{s}} \rho_{\mathrm{s}} / 3 \alpha_{\mathrm{u}} \mathrm{c}_{\mathrm{p}} \rho_{\mathrm{g}}\right)\right] / \tau_{\mathrm{c}}$ is a ratio of the characteristic particle heat exchange time and combustion time of the particle (with $r$ radius) that is close to unity for nonvolatile and Lewis number $(\operatorname{Le}=1)$. The boundary conditions for the above differential equations are as following:

$$
\left\{\begin{array}{l}
\mathrm{y} \rightarrow-\infty \Rightarrow \theta=\theta_{\mathrm{s}}=1, \mathrm{y} \rightarrow+\infty \Rightarrow \theta=1 \\
\mathrm{y}=0 \Rightarrow \theta_{\mathrm{s}}=\theta_{\mathrm{s}}{ }_{\mathrm{s}}^{\mathrm{i}},\left.\theta\right|_{0^{-}}=\left.\theta\right|_{0^{+}}, \mathrm{d} \theta /\left.\mathrm{dy}\right|_{0^{-}}=\mathrm{d} \theta /\left.\mathrm{dy}\right|_{0^{+}}
\end{array}\right.
$$

By solving this heat transfer equations in each flame zone and by matching the heat fluxes obtained from these solutions on the boundary of each zone the algebraic equation for the nondimensional flame speed $(\mathrm{k})$ is found to be:

$$
\frac{1}{\mu \varphi}=\frac{\mathrm{K}_{1}-\mathrm{k \eta}}{\mathrm{K}_{1}\left(1+\mathrm{K}_{1} \xi\right)(\mathrm{k}(1-\eta)+1)} \frac{1-\exp \left(-\mathrm{K}_{1}\right)}{\sqrt{1+4 \frac{\eta}{\mathrm{k}}}}
$$

where

$$
\mathrm{K}_{1}=\frac{\mathrm{k}}{2}\left(1+\sqrt{1+4 \frac{\eta}{\mathrm{k}}}\right)
$$

For a mono-dispersed particle laden flow, the flame speed increases by increasing particle concentration under fuel-lean conditions. As in a monosize suspension, parameters $\mu_{\mathrm{i}}(\mathrm{i}=1,2)$ are the dimensionless mass dust concentrations of corresponding dusts and $\mathrm{k}_{\mathrm{i}}=\mathrm{s}_{\mathrm{L}}^{2} \tau_{\mathrm{ci}} / \mathrm{a}_{\mathrm{u}}$ is the dimensionless flame speed. Also parameter $\mathrm{p}=\tau_{\mathrm{c} 2} / \tau_{\mathrm{c} 1}$ is the ratio of combustion times of the first and the second dusts. For convenience, we will also assign the number 1 to the dust with a lower particle ignition temperature. In dual-sized aluminum-particle/air suspensions, the flames have a complex multistage structure. All possible configurations of the stationary flame front in binary suspension of previous model ${ }^{[15,16]}$ were contained five zones which in new model decrease to three zones (the lower step corresponds to the number 1 dust). In reaction zone II micro and nano particle combust in overlap configuration.

For nano particles, reaction rate value at $\mathrm{y}=0$ is considered to be equal $\sigma_{1} / \tau_{\mathrm{cl} 1}$ and final reaction rate equation is obtained as:

$$
\mathrm{W}_{\mathrm{F} 1}(\mathrm{y})=\frac{\sigma_{1}}{\tau_{\mathrm{cl}}} \mathrm{e}^{-\mathrm{y}}
$$

Micro particles do not ignite at $\mathrm{y}=0$ because of high ignition temperature compare with nano scale. They ignite at another point such as $\mathrm{z}$ that is depended on size distribution and concentration of particles. The reaction rate value at $\mathrm{y}=\mathrm{z}$ is considered to be equal $\sigma_{2} / \tau_{\mathrm{c} 2}$ :

$$
\mathrm{W}_{\mathrm{F} 2}(\mathrm{y})=\frac{\sigma_{2}}{\tau_{\mathrm{c} 2}} \mathrm{e}^{-\mathrm{y}+\mathrm{z}}
$$

The heat transfer equation for new flame configuration shown schematically in Fig. 1 can be written in the same form as Eq. 10 for a binary suspension:

$$
\begin{aligned}
& \frac{\mathrm{d}^{2} \theta}{\mathrm{dy} \mathrm{y}^{2}}-\mathrm{k} \frac{\mathrm{d} \theta}{\mathrm{dy}}=\mathrm{k} \eta(\theta-1)+ \\
& \mathrm{W}\left\{\begin{array}{l}
0, \text { combustion is absent } \\
-\mathrm{k} \mu_{1}\left(\theta_{\mathrm{s} 1}^{\mathrm{i}}-1\right) \exp (-\mathrm{y}), \text { only the first dust burns } \\
-\mathrm{k} \mu_{1}\left(\theta_{\mathrm{s} 1}^{\mathrm{i}}-1\right) \exp (-\mathrm{y})-\mathrm{k} \mu_{2}\left(\theta_{\mathrm{s} 2}^{\mathrm{i}}-1\right) \exp (-\mathrm{y}+\mathrm{z}) \\
\text { both dust burn }
\end{array}\right.
\end{aligned}
$$




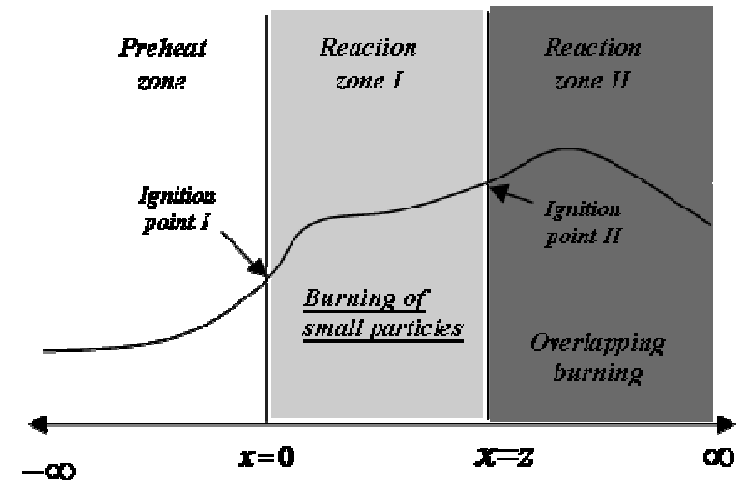

Fig. 1: Structure of flame in binary suspension with new reaction rate model

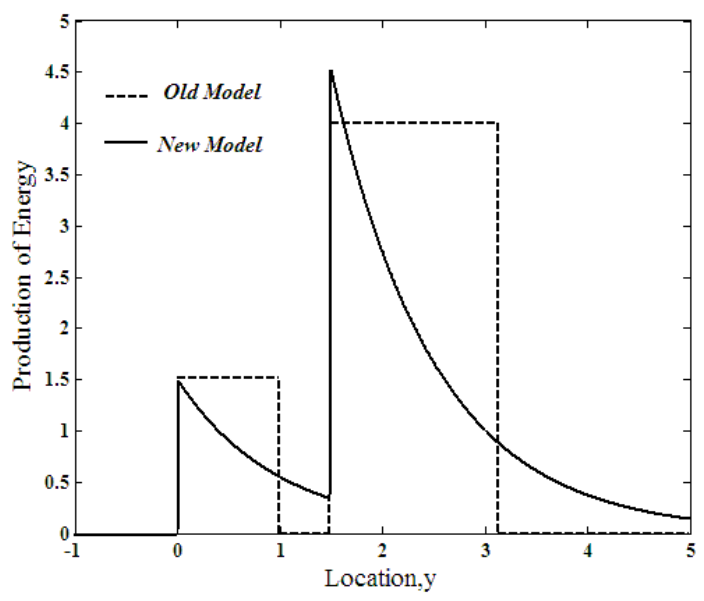

Fig. 2: Comparing the production of energy in new and old model for bimodal Nano/Micro dust suspension

The difference between three equation shows in Eq. 17 is in term of production of energy. In Fig. 2 we can observe the effect of new reaction rate model in this term. The energy conservation equation for the particle phase is:

$$
\begin{aligned}
& \frac{\mathrm{d} \theta_{\mathrm{s} 1}}{\mathrm{dy}}=\frac{\left(\theta-\theta_{\mathrm{s} 1}\right)}{\xi_{1}} \\
& \frac{\mathrm{d} \theta_{\mathrm{s} 2}}{\mathrm{dy}}=\frac{\left(\theta-\theta_{\mathrm{s} 2}\right)}{\xi_{2}}
\end{aligned}
$$

where

$$
\mu_{1}=\sigma_{1} \mathrm{Q} / \mathrm{c}_{\mathrm{p}} \rho_{\mathrm{gu}}\left(\mathrm{T}_{\mathrm{sl}}^{\mathrm{i}}-\mathrm{T}_{\mathrm{u}}\right)
$$

$$
\begin{aligned}
& \mu_{2}=\sigma_{2} \mathrm{Q} / \mathrm{c}_{\mathrm{p}} \rho_{\mathrm{gu}} \mathrm{p}\left(\mathrm{T}_{\mathrm{s} 2}^{\mathrm{i}}-\mathrm{T}_{\mathrm{u}}\right) \\
& \xi_{1}=\left[\left(\mathrm{r}_{1}^{2} \mathrm{c}_{\mathrm{s}} \rho_{\mathrm{s}} / 3 \mathrm{a}_{\mathrm{u}} \mathrm{c}_{\mathrm{p}} \rho_{\mathrm{g}}\right)\right] / \tau_{\mathrm{c} 1} \\
& \xi_{2}=\left[\left(\mathrm{r}_{2}^{2} \mathrm{c}_{\mathrm{s}} \rho_{\mathrm{s}} / 3 \mathrm{a}_{\mathrm{u}} \mathrm{c}_{\mathrm{p}} \rho_{\mathrm{g}}\right) \mathrm{p}\right] / \tau_{\mathrm{c} 2}
\end{aligned}
$$

The boundary condition of the Eq. 17, 18 and 19 is:

$$
\left\{\begin{array}{l}
\mathrm{y} \rightarrow-\infty, \theta=\theta_{\mathrm{s}}=1 \\
\mathrm{y}=0, \theta_{\mathrm{s} 1}=\theta_{\mathrm{s} 1}{ }^{\mathrm{i}},\left.\theta\right|_{0^{-}}=\left.\theta\right|_{0^{+}}, \mathrm{d} \theta /\left.\mathrm{dy}\right|_{0^{-}}=\mathrm{d} \theta /\left.\mathrm{dy}\right|_{0^{+}} \\
\mathrm{y}=\mathrm{z}, \theta_{\mathrm{s} 2}=\theta_{\mathrm{s} 2}^{\mathrm{i}},\left.\theta\right|_{\mathrm{z}^{-}}=\left.\theta\right|_{\mathrm{z}^{+}}, \mathrm{d} \theta /\left.\mathrm{dy}\right|_{\mathrm{z}^{-}}=\mathrm{d} \theta /\left.\mathrm{dy}\right|_{\mathrm{z}^{+}} \\
\mathrm{y} \rightarrow+\infty, \theta=1
\end{array}\right.
$$

By solving the energy equation for each zone and matching the resultant temperature and heat flux at the interfacial boundaries, the algebraic equations for the flame speed and parameter $\mathrm{Z}$ (the nondimensional distance between ignition point) can be obtained:

$$
\begin{gathered}
\mathrm{z}=-\frac{1}{\mathrm{~K}_{1}} \ln \left[\begin{array}{l}
-\frac{\theta_{\mathrm{s} 1}^{\mathrm{i}}-1}{\theta_{\mathrm{s} 2}^{\mathrm{i}}-1} \\
\left(\frac{\left(\mathrm{K}_{1}-\mathrm{K}_{2}\right)\left(1+\mathrm{K}_{1} \zeta_{1}\right)[(\eta-1) \mathrm{k}-1]}{\mathrm{k} \mu_{2}\left(\mathrm{~K}_{2}+1\right)}+\frac{\mu_{1}}{\mu_{2}}\right)
\end{array}\right] \\
\frac{\mu_{2}}{\mu_{1}}=\frac{\theta_{\mathrm{s} 1}^{\mathrm{i}}-1}{\theta_{\mathrm{s} 2}^{\mathrm{i}}-1}\left[\frac{\mathrm{M}_{1}}{\mathrm{M}_{2}}\right]
\end{gathered}
$$

where, $\mathrm{M}_{1}, \mathrm{M}_{2}$ and $\mathrm{k}_{2}$ is defined as follow:

$$
\begin{aligned}
& \mathrm{M}_{1}= \frac{[(\eta-1) \mathrm{k}-1] \exp \left(-\mathrm{z} / \zeta_{2}\right)}{\left(1+\mathrm{K}_{1} \zeta_{2}\right)\left(1+\mathrm{K}_{2} \zeta_{2}\right)\left(1-\zeta_{2}\right)} \\
&+\frac{\left(\mathrm{K}_{1}+1\right) \exp \left(\mathrm{K}_{2} \mathrm{z}\right)}{\left(\mathrm{K}_{2}-\mathrm{K}_{1}\right)\left(1+\mathrm{K}_{2} \zeta_{2}\right)}+\frac{\exp (-\mathrm{z})}{1-\zeta_{2}} \\
& \mathrm{M}_{2}= \frac{(\eta-1) \mathrm{k}-1}{\mathrm{k} \mu_{2}}+\frac{\mathrm{K}_{2}+1}{\left(\mathrm{~K}_{1}-\mathrm{K}_{2}\right)\left(1+\mathrm{K}_{1} \zeta_{2}\right)} \\
& \mathrm{K}_{2}=\frac{\mathrm{k}}{2}\left(1-\sqrt{1+4 \frac{\eta}{\mathrm{k}}}\right)
\end{aligned}
$$

By solving sets of Eq. 25 and 26 we can obtain the value of $\mathrm{k}$ and $\mathrm{z}$ for different concentration of nano and micro particles. 


\section{RESULTS AND DISCUSSIONS}

Of course the behavior of Aluminum dust particles are influenced by different agents. Comparing the achieved results indicate that the increasing in concentration of particles in Aluminum dust combustion results in increasing of flame speed and combustion intensity. Fig. 3 show the decreasing of $\eta$ which also indicates the rate of heat loss causes the increasing of flame speed. And in adiabatic case in which heat loss is zero, the flame speed is max. In other hand in many causes of experiment results ${ }^{[12-14]}$, the flame speed is less than analytical results. One reason can be of not considering the effect of radiation in heat loss. Fig. 4 shows the flame speed variation according to equivalence ratio $\varphi$ for heat loss, that is $\eta$ $=0.01$. And it is observed that the new model (with current reaction rate) in comparing with the old model belonged to Bidabadi et al. ${ }^{[20]}$ (with constant reaction rate) is nearer to the experimental results, which can indicate a better reaction rate. Results indicate that the main difference between reaction rate proportional to amount of fuel and previous model ${ }^{[19]}$ is in reaction zone. In so called region as post flame zone (according to previous model) gas temperatures overlap each other. Also as it is observed in Fig. 5 there is no great different between temperature profiles in preheat zone. It shows the temperature profiles in Fig. 6 for different values of heat loss parameter $(\eta)$ which reasonably the flame temperature decreases when heat loss parameter increases. In preheat zone, the flame temperature was shown to be a weak function of heat loss parameter, a

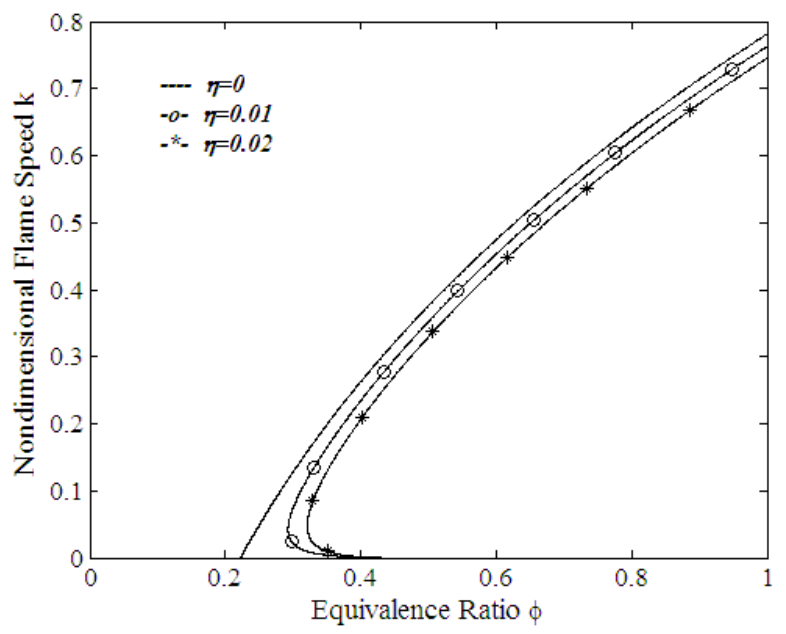

Fig. 3: Dependence of non-dimensional flame speed $\mathrm{k}$ to equivalence ratio at different value of $\eta$

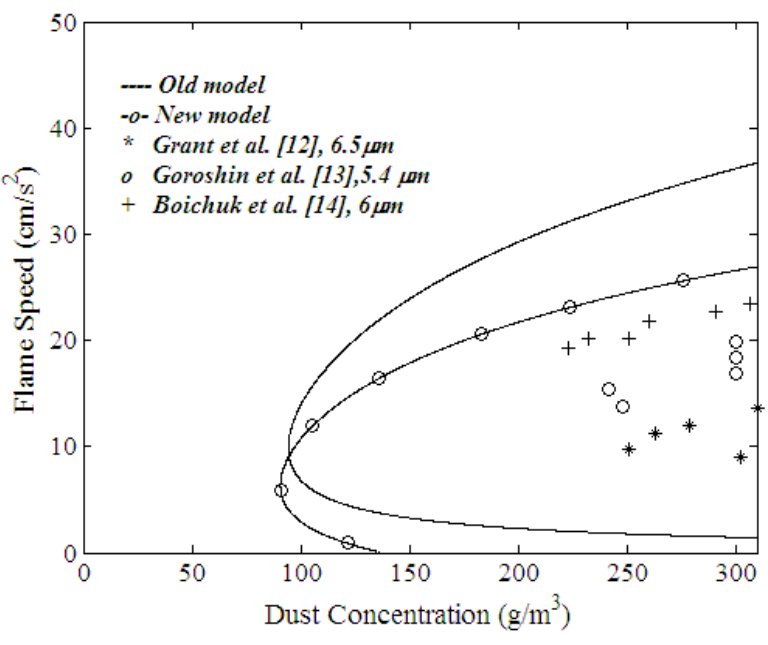

Fig. 4: Dependence of flame speed to dust concentration

phenomenon that can be attributed to the weak dependence of flame temperature on the heat loss parameter. It's because of low temperature difference between gas and wall in this zone.

The nondimensional flame speed of bimodal particle mixture obtained from Eq. 25 and 26 is mapped in Fig. 7 in relation to mixture composition and initial mass concentration of the first and second dust in the suspension. Particles diameters are $100 \mathrm{~nm}$ and $6.5 \mu \mathrm{m}$ and corresponding ignition temperature is $\theta_{\mathrm{s} 1}{ }^{\mathrm{i}}=4$ and $\theta_{\mathrm{s} 2}{ }^{i}=7$, respectively. The results have a good agreement with the result of Y.Huang et al. ${ }^{[16]}$. According to Fig. 8 in which increasing $\mu_{1}$ and $\mu_{2}$ the value of $\mathrm{k}$ is increased and in concentration with are

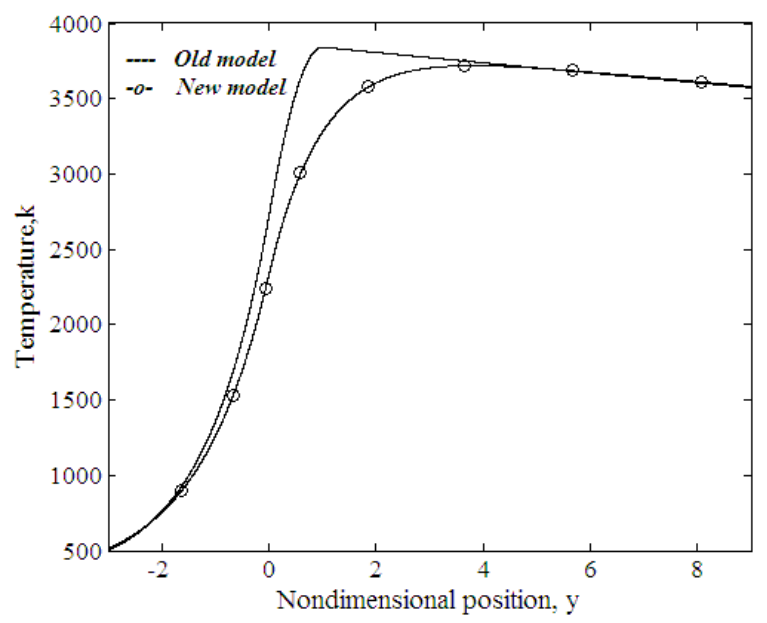

Fig. 5: Comparing the temperature profiles in two models 
Am. J. Engg. \& Applied Sci., 1 (4): 295-301, 2008

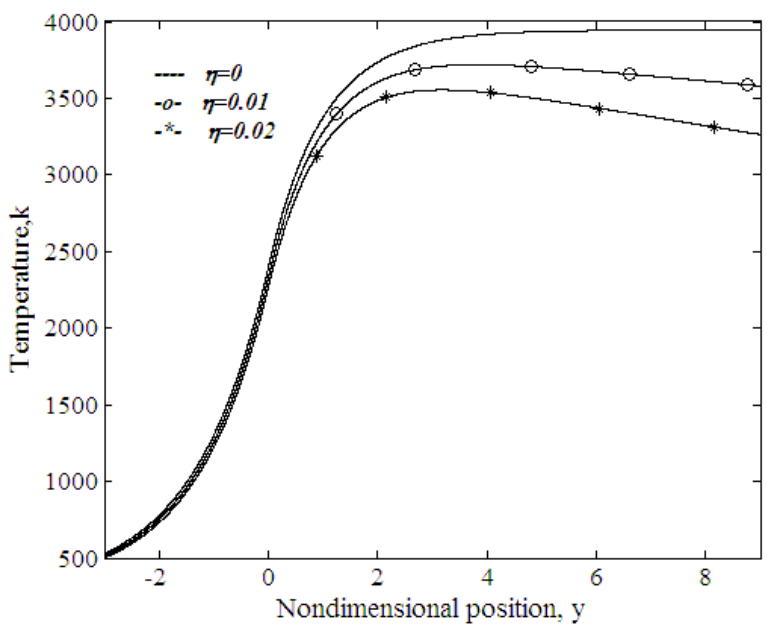

Fig. 6: Temperature profiles with different value of $\eta$

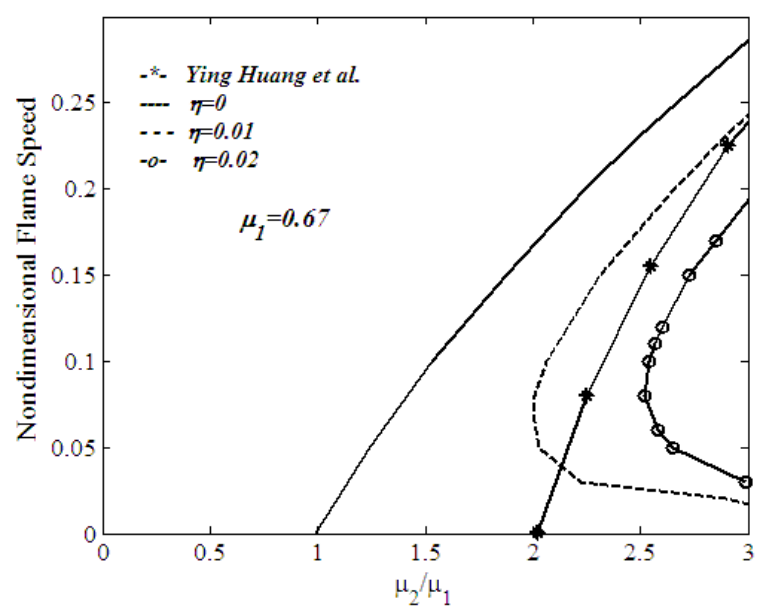

Fig. 7: Nondimensional flame speed per $\mu_{2} / \mu_{1}$ at different value of $\eta, \mu_{1}=0.67$

shown as dots the micro particles don't inter the reaction which is in agreement with the results $\mathrm{in}^{[15]}$.

\section{CONCLUSION}

In this study, a simple analytical model of binary suspension of nano/micro-sized aluminum particles with heat losses and reaction rate is studied. Since there exists heat losses to walls in reality (non-adiabatic); thus ignoring this term does not indicate real case. Also real polydisperse dusts by some average particles size are not adequate for flame propagation models; thus flames in the real dust suspension can be extended into a description of the multisize dust combustion and previous models have been solved for average particles size or multisize dust without heat losses to walls.
Reasonable agreement between theoretical results and experimental data is obtained in terms of flame speed. Flame speeds with heat losses and reaction rate proportional to available amount of fuel reported in this study are slightly lower that Goroshin et $a l^{[14]}$ and Bidabadi et al..$^{[20]}$ and reasonably the flame speed decreases when heat loss parameter increases. It can be also considered the reason of decreasing of flame speed in compare with the former model is becoming bigger than the reaction zone and increasing a large amount of reaction rate in the beginning of reaction zone.

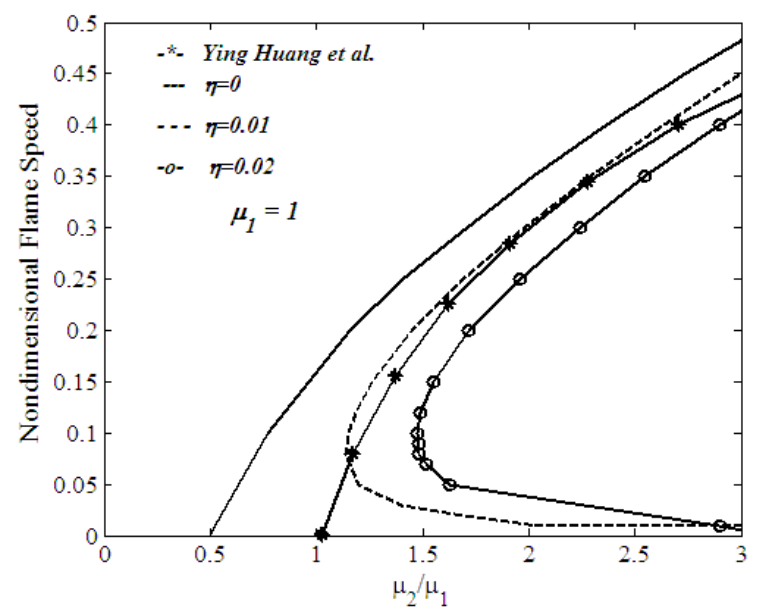

Fig. 8: Nondimensional flame speed per $\mu_{2} / \mu_{1}$ at different value of $\eta, \mu_{1}=1$

\section{REFERENCES}

1. Kornilov, V.N., A.V. Korobko and E.N. Kondratyev, 2006. A correlation function method of recovering the combustion law parameters for particles burning in optically thin dust flames: Combus. Flame, 146: 530-540.

2. Eapen, B.Z., V.K. Hoffmann, M. Schoenitz and E.L. Dreizin, 2004. Combustion of aerosolized spherical aluminum powders and flakes in air: Combust. Sci. Tech., 176: 1055-1069.

3. Seshadri, K., A.l. Berland and V. Tangirala, 1992. The structure of premixed particle-cloud flames: Combus. Flame, 89: 333-342.

4. Rai, A., K. Park, L. Zhou and M.R. Zachariah, 2006. Understanding the mechanism of aluminum nanoparticle oxidation: Combust. Theory Modeling, 10: 843-859.

5. Friedman, R. and A. Macek, 1962. Ignition and combustion of aluminum particles in hot ambient gases: Combus. Flame, 6: 9-19. 
6. Kwon, Y.S., A.A. Gromov, A.P. Ilyin, E.M. Popenko and G.H. Rim, 2003. The mechanism of combustion of superfine aluminum powders: Combus. Flame, 133: 385-391.

7. Bucher, P., R.A. Yetter, F.L. Dryer, E.P. Vicenzi, T.P. Parr and D.M. Hanson-parr, 1999. Condensedphase species distributions about al particles reacting in various oxicizer: Combus. Flame, 117: 351-361.

8. Dreizin, E.L., 1996. Experimental study of stages in aluminum particle combustion in air: Combus. Flame, 105: 541-556.

9. Dreizin, E.L., 2003. Effect of phase changes on metal particle combustion processes: Combustion, Explosion and Shock Waves, 39: 92-96.

10. Tambour, Y., 1985. A lagrangian sectional approach for simulating droplet size distribution of vaporizing fuel sprays in a turbulent jet: Combus. Flame, 44: 15-28.

11. Greenberg, J.B. and I. Shpilberg, 1995. Transient behavior in the evolution of laminar multisize spray diffusion flames: Atomiz. Sprays, 5: 507523. www.edatacenter.com/journals/6a7c7e10642258cc,51ad999c0 312b78b,5100c9fe0f01d91e.html.

12. Risha, G.A., Y. Huang, R.A. Yetter and V. Yang, 2005. Experimental investigation of aluminum particle dust cloud combustion under various oxidizing environments: AIAA Paper. http://spaceops2006.org/agenda.cfm?lumeetingid= $666 \&$ formatview $=1 \&$ dateget $=11-\mathrm{Jan}-05$.

13- S. Goroshin, I. Fomenko, J.H.S. Lee, 1996. Burning Velocity in Fuel-Rich Aluminum Dust Clouds: Proceed. Combust. Instit., 26: 1961-1967.

14- L.V., Boichuk, V.G. Shevchuk and A.I. Shvets, 2002. Flame Propagation in Two-Component Aluminum-Boron Gas Suspensions: Combust. Explo. Shock Waves, 38 (6): 651-654. http://www.ingentaconnect.com/content/klu/cesw/2 002/00000038/00000006/00458790

15. S. Goroshin, M. Kolbe, J.H.S. Lee, 2000. Flame Speed in a Binary Suspension of Solid Fuel Particles: Proceed. Combust. Instit., 28: 28112817.

16. Huang, Y., Grant A.Risha, Vigor Yang, Yetter,R., 2007 Combustion of bimodal nano/micron-sized aluminum particle dust in air: Proceed. Combust. Instit., 31 (2), 2001-2009
17. Y. Shoshin, E.L. Dreizin, 2003. Particle combustion rates in premixed flames of polydisperse metal - air aerosols: Combus. Flame, 133: 273-287.

18. Y. Shoshin, E.L. Dreizin, 2006. Particle combustion rates for mechanically alloyed Al-Ti and aluminum powders burning in air: Combus. Flame, 145: 714-722.

19. S. Goroshin, M. Bidabadi, Lee, J. H. S., 1996. Quenching Distance of Laminar Flame in Aluminum Dust Clouds: Combus. Flame, 105: 147-160.

20. M. Bidabadi, N. Moallemi, A. Armin, I. Shafieenejad, 2008. The Investigation of Flame Speed and Temperature in Flames of Aluminum Micro and Nano-Particle Clouds: Int.l Review Mech. Eng., 2(3). http://www.praiseworthyprize.com/IREME_latest. html.

21. Jarosinski, J., 1986. A survey of Recent studies on Flame Extinction: Prog. Energy Combustion Sci., 12: 81-116.

22. Y. Huang, G.A.Risha, V. Yang, Richard A. Yetter, 2005. Analysis of Nano-Aluminum Particle Dust Cloud Combustion in Different Oxidizer Environments: $43^{\text {th }}$ Aerospace science Meeting and Exhibit. http://pdf.aiaa.org/preview/CDReadyMASM05_66 6/PV2005_738.pdf.

http://www.aric.or.kr/treatise/journal/content.asp?i $\mathrm{dx}=63847 \&$ Search $=$ Y.\%20Park\&Select_field $=$ Aut hor\&SearchVal=Y.\%20Park\&SearchCheck=\&pag $\mathrm{e}=2$.

23. G. Joulin, 1980. Temperature-Lags and Radiative Transfer in Particle-Laden Gaseous Flames, Part I: Steady Planar Flames: Combust. Science Tech, 18: 1395-1403.

24. G. Joulin, 1987. Asymptotic Analysis of NonAdiabatic Flames, Heat Losses towards Small Inert Particles: Proceed. Combust. Instit., 18: 13951403. 